\title{
Improved Dielectric Properties and Grain Boundary Response in Neodymium-doped $\mathrm{Y}_{2 / 3} \mathrm{Cu}_{3} \mathrm{Ti}_{4} \mathrm{O}_{12}$ Ceramics
}

\section{Pengfei Liang, Zupei Yang*, Xiaolian Chao}

Key Laboratory for Macromolecular Science of Shaanxi Province

School of Materials Science and Engineering, Shaanxi Normal University, Xi'an, 710062, Shaanxi, P.R. China

*Corresponding:

Key Laboratory for Macromolecular Science of Shaanxi Province

School of Materials Science and Engineering

Shaanxi Normal University, Xi'an, 710062, Shaanxi, P.R. China

Tel: +86-29-81530-718; Fax: +86-29-81530-702

E-mail address: yangzp@snnu.edu.cn; 


\begin{abstract}
Rare earth element neodymium was adopted to refine grain and in turn increase the volume of grain boundary of $\mathrm{Y}_{2 / 3} \mathrm{Cu}_{3} \mathrm{Ti}_{4} \mathrm{O}_{12}$ ceramics, which could strongly increase the resistance of grain boundary. Proper amount of $\mathrm{Nd}$ substitution in $\mathrm{Y}_{2 / 3-x} \mathrm{Nd}_{x} \mathrm{Cu}_{3} \mathrm{Ti}_{4} \mathrm{O}_{12}$ ceramics could significantly depress the low-frequency dielectric loss. When the doping level is 0.06 and 0.09 , the samples exhibited a relatively low dielectric loss (below 0.050 between 0.3 and $50 \mathrm{kHz}$ ) and high dielectric constant above 11000 over a wide frequency range from $40 \mathrm{~Hz}$ to $100 \mathrm{kHz}$. Based on the $\varepsilon^{\prime}-T$ plots, dielectric relaxation intensity was substantially weakened by $\mathrm{Nd}$ doping so that the temperature stability of dielectric constant was improved obviously. The correlations between low-frequency dielectric loss and the resistance of grain boundary were revealed. After Nd doping, the activation energies for the conduction behavior in grain boundaries were significantly enhanced, and the activation energies for the dielectric relaxation process in grain boundaries were slightly influenced.
\end{abstract}

Keywords: Giant permittivity; Low dielectric loss; Grain boundary response; Dielectric properties; Electrical conductivity; Electrical modulus 


\section{Introduction}

The search for new high performance dielectric materials, exhibiting temperatureand frequency-stable, colossal permittivity $\left(\varepsilon_{\mathrm{r}}>1000\right)$ as well as sufficiently low dielectric loss, continues to arouse considerable interest motivated by their myriad device miniaturization and high-energy-density storage applications [1-3]. In recent years, $\mathrm{Y}_{2 / 3} \mathrm{Cu}_{3} \mathrm{Ti}_{4} \mathrm{O}_{12}$ (YCTO) ceramics, as a member of the $\mathrm{ACu}_{3} \mathrm{Ti}_{4} \mathrm{O}_{12}$ compounds, were reported to exhibit a giant dielectric constant $\left(\varepsilon_{\mathrm{r}}>10000\right)$ with a relatively low dielectric loss $(0.033$ at $1 \mathrm{kHz})$ and a good temperature stability [4]. Although the dielectric loss of YCTO ceramics is much lower than that of CCTO ceramics, it is still much larger than the standard acceptable value for capacitor applications. The value of loss tangent $(\tan \delta)$ is one of the most important parameters determining a dielectric material's suitability for capacitor application. In general, the low-frequency dielectric loss is closely correlated to electrical conductivity $\left(\sigma_{\mathrm{dc}}\right)$ caused by long-range motion of charge carriers $[5,6]$. According to the IBLC structure, low-frequency $\tan \delta$ can be depressed substantially by increasing the total resistance of the bulk ceramics. This can be achieved by increasing the resistance of the insulating grain boundaries due to the fact that the grain resistance $\left(R_{g}\right)$ is much lower than that of the grain boundary $\left(R_{g b}\right)$ [7-9]. As we know, changes in the macroscopic properties of the grain boundary to depress $\sigma_{\mathrm{dc}}$ and $\tan \delta$ could be mainly divided into two approaches, i.e., geometric and intrinsic factors. The former one can be achieved by controlling the microstructure to obtain a small grained microstructure with a high density grain boundary [10-14]. The latter one is to enhance the resistivity of individual grain boundary by tuning the 
electronic structure at the interface between grain and grain boundary [15-16]. Owing to larger ion radius of rare earth element, rare earth ions doping usually gives rise to a decrease in mean grain size of samples so that inducing a higher density of grain boundaries $[14,20]$. Therefore, it is anticipated that the introduction of the $\mathrm{Nd}$ ions to the $\mathrm{Y}$ sites in YCTO ceramics would refine grain size and successfully tune the resistances of grain boundary as well as realize the decrease of the low-frequency dielectric loss.

In this work, $\mathrm{Nd}$-doped $\mathrm{Y}_{2 / 3-x} \mathrm{Nd}_{x} \mathrm{Cu}_{3} \mathrm{Ti}_{4} \mathrm{O}_{12}(x=0.00,0.03,0.06,0.09$, and 0.12$)$ ceramics were prepared, and their dielectric and electric properties were investigated systematically. The related mechanism of the decreased dielectric loss was proposed. Especially, based on electric modulus and electrical conductivity analysis, the electrical conduction and dielectric relaxation behaviors of the grain boundary effects in $\mathrm{Y}_{2 / 3-x} \mathrm{Nd}_{x} \mathrm{Cu}_{3} \mathrm{Ti}_{4} \mathrm{O}_{12}$ ceramics were clarified in detail. 


\section{Experimental Procedure}

$\mathrm{Y}_{2} \mathrm{O}_{3}(99.99 \%), \mathrm{Nd}_{2} \mathrm{O}_{3}(99.99 \%), \mathrm{TiO}_{2}(99.99 \%)$, and $\mathrm{CuO}(99 \%)$ were used as raw materials to prepare $\mathrm{Y}_{2 / 3-x} \mathrm{Nd}_{x} \mathrm{Cu}_{3} \mathrm{Ti}_{4} \mathrm{O}_{12}(x=0.00,0.03,0.06,0.09$, and 0.12$)$ ceramics by the conventional mixed-oxide method. The stoichiometric powders were mixed by ball-milling in the alcohol for $10 \mathrm{~h}$, then dried and calcined at $930{ }^{\circ} \mathrm{C}$ for $10 \mathrm{~h}$ in air. The calcined mixture was ball-milled again for another $10 \mathrm{~h}$ and then pressed into disk pellets with a diameter of $15 \mathrm{~mm}$ under $100 \mathrm{MPa}$ pressure. The pellets were sintered in air at $1000-1050{ }^{\circ} \mathrm{C}$ for $25 \mathrm{~h}$ depending on the composition.

The phase structure of sintered ceramics was characterized by X-ray diffraction (XRD, D/max-2550/PC, Rigaku, Japan) technique using $\mathrm{Cu} \mathrm{K} \alpha$ radiation. The microstructure of sample surfaces were viewed using scanning electron microscopy (SEM, Quanta 200, FEI Co., Eindhoven, the Netherlands). After being polished and pasted by silver paste on both sides, the ceramic samples were then treated at $840{ }^{\circ} \mathrm{C}$ for 30 min to form the electrodes for electrical measurements. Dielectric dispersion and complex impedance were measured by Agilent 4294A (Palo Alto, CA) impedance analyzer in the frequency range of $40 \mathrm{~Hz}-110 \mathrm{MHz}$ over the temperature range of 30-340 ${ }^{\circ} \mathrm{C}$. Temperature dependence of dielectric constant and loss was measured by the LCR meter (Agilent E4980A) from ambient temperature to $400{ }^{\circ} \mathrm{C}$ at $1,10,100$, and $1000 \mathrm{kHz}$, respectively. 


\section{Results and Discussion}

Fig. 1 shows the XRD patterns of the as-sintered $\mathrm{Y}_{2 / 3-} \mathrm{Nd}_{x} \mathrm{Cu}_{3} \mathrm{Ti}_{4} \mathrm{O}_{12}(x=0.00$, $0.03,0.06,0.09$, and 0.12) ceramics. All the major diffraction peaks in the XRD patterns can be indexed by a body centered cubic perovskite-related structure of space group Im $\overline{3}$ according to JCPDS \# 75-2188 and no secondary phase can be detected even with $x$ up to 0.12 of nominal compositions. With increasing Nd doping level, all diffraction peaks gradually shift toward lower angles. The magnified (220) peaks clearly show this variation trend. It means the lattice parameters increase with increasing $\mathrm{Nd}$ content. This could be explained by the cation substitution, i.e.,a process of $\mathrm{Nd}^{3+}$ substituting $\mathrm{Y}^{3+}$ ion, due to the fact that the $\mathrm{Nd}^{3+}$ and $\mathrm{Y}^{3+}$ ionic radii at 8-fold coordinate are 0.109 and $0.102 \mathrm{~nm}$. Fig. 2 shows the SEM images of the surfaces of $\mathrm{Y}_{2 / 3-x} \mathrm{Nd}_{x} \mathrm{Cu}_{3} \mathrm{Ti}_{4} \mathrm{O}_{12}$ ceramics. It can be seen that all the sintered samples show a dense microstructure with low porosity. The relative density of $\mathrm{Y}_{2 / 3-x} \mathrm{Nd}_{x} \mathrm{Cu}_{3} \mathrm{Ti}_{4} \mathrm{O}_{12}$ ceramics with $x=0.00,0.03,0.06,0.09$, and 0.12 are $97.6 \%, 97.9 \%$, $98.3 \%, 98.6 \%$, and $98.1 \%$, respectively. The rare earth $\mathrm{Nd}$ dopant, as grain growth inhibitor, has an evident effect on the grain size reduction. The mean grain sizes of $\mathrm{Y}_{2 / 3-x} \mathrm{Nd}_{x} \mathrm{Cu}_{3} \mathrm{Ti}_{4} \mathrm{O}_{12}$ ceramics with $x=0.00,0.03,0.06,0.09$, and 0.12 are 18, 16, 14, 10 , and $6 \mu \mathrm{m}$, respectively. This indicates that $\mathrm{Nd}$ substituted ions of large radius are more difficult to enter the unit cell of crystal lattice and more efficient to suppress the grain growth than $\mathrm{Y}$ ions of small radius. Furthermore, it is evident that an obvious mixture of various grain sizes is observed at $x=0.12$, which shows large grains coexist with very small ones. The SEM images verify that Nd doping has an effect on the decrease in 
grain size of YCTO ceramics and in turn gives rise to an increase in the density of grain boundaries.

Significant suppression of the grain growth in Nd-doped YCTO ceramics is likely associated with the solute drag mechanism which is an important phenomena to investigate the depressed grain boundary mobility in polycrystalline ceramics $[21,22]$. It is known that the difference in ionic radii between dopant and host ions will introduce lattice strain energy $\left(\Delta G_{\text {strain }}\right)$ in the crystal lattice, following to the relation $\Delta G_{\text {strain }}=4 \pi E N_{A}\left[\left(r_{0} / 2\right)\left(r_{M}-r_{0}\right)^{2}+(1 / 3)\left(r_{M}-r_{0}\right)^{3}\right]$ where $r_{0}$ and $r_{M}$ represent the optimal radius of the lattice site and the ionic radius of dopant, respectively. $N_{A}$ is Avogadro's Number, $E$ is Young's modulus [21,23]. $\quad \Delta \mathrm{G}_{\text {strain }}$ induced by size mismatch between the dopant $\mathrm{Nd}^{3+}$ ions and host $\mathrm{Y}^{3+}$ ions together with the electrostatic potential energy at grain boundary could give rise to interaction between the boundary and the dopant $[21,24]$. As a result, the grain growth of Nd-doped samples was inhibited significantly.

Fig. 3(a) shows the frequency dependence of the real part $\varepsilon^{\prime}$ of the dielectric constant, and the inset shows the expanded view of low-frequency dielectric constant of $\mathrm{Y}_{2 / 3-x} \mathrm{Nd}_{x} \mathrm{Cu}_{3} \mathrm{Ti}_{4} \mathrm{O}_{12}$ ceramics. It is clearly shown in Fig. 3(a) that all ceramics exhibit considerable high dielectric constant in the low frequency range from $40 \mathrm{~Hz}$ to $\sim 100$ $\mathrm{kHz}$. As the measuring frequency further increases to $1 \mathrm{MHz}$, a dramatical decrease in dielectric constant occurs, which is frequently observed in IBLC structure materials. These features are attributed to a Maxwell-Wagner relaxation behavior. When the frequency is above $30 \mathrm{MHz}$, another dielectric constant plateau occurs, which is attributed to the bulk response, i.e., intrinsic dielectric response [25]. From the inset of 
Fig. 3(a), it is noted that $\mathrm{Nd}$ doping induces a slight decrease in the low-frequency dielectric constant and reduces the frequency dependence of dielectric constant compared to the un-doped sample. Furthermore, when $x \leq 0.09$, the low frequency dielectric constant value is beyond 11000 in a wide frequency range from $40 \mathrm{~Hz}$ to 100 kHz. Fig. 3(b) exhibits the frequency dependence of the dielectric loss tan $\delta$, and the inset shows the expanded view of low-frequency dielectric loss of $\mathrm{Y}_{2 / 3-x} \mathrm{Nd}_{x} \mathrm{Cu}_{3} \mathrm{Ti}_{4} \mathrm{O}_{12}$ ceramics. Corresponding to an abrupt decrease in dielectric constant at $1 \mathrm{MHz}$, dielectric loss peaks are observed in the frequency dependence of dielectric loss plots, which is associated with the grain response. It can be seen from the inset of Fig. 3(b) that the low-frequency dielectric loss is strongly influenced by $\mathrm{Nd}$ doping. At $x=0.06$ and 0.09 , the low frequency-dielectric loss reaches to the lowest value, and in a wide frequency range from 0.3 to $50 \mathrm{kHz} \tan \delta$ is below 0.050 , which is much lower than that of pure CCTO and YCTO ceramics. The dielectric loss of $\mathrm{Y}_{2 / 3-x} \mathrm{Nd}_{x} \mathrm{Cu}_{3} \mathrm{Ti}_{4} \mathrm{O}_{12}$ ceramics at $1 \mathrm{kHz}$ with $x=0.00,0.03,0.06,0.09$, and 0.12 are $0.058,0.048,0.032$, 0.030, and 0.046, respectively. According to above analysis, it can be concluded that proper amount of $\mathrm{Nd}^{3+}$ substitution at $\mathrm{Y}$ site can significantly lower the low-frequency dielectric loss of the YCTO ceramics, and also keep the dielectric constant at a relatively high value.

Complex impedance study is an informative and useful characterisation technique in materials research that provides vital information regarding the microstructure of polycrystalline materials, such as grains, grain boundaries, surface layers and electrode interfaces [25,26]. Fig. 4(a) demonstrates the complex impedance plots of 
$\mathrm{Y}_{2 / 3-x} \mathrm{Nd}_{x} \mathrm{Cu}_{3} \mathrm{Ti}_{4} \mathrm{O}_{12}$ ceramics, and the inset exhibits an expanded view of high frequency data close to the origin. All samples show a large semi-circular arc and a small semi-circular arc within the measuring frequency range of $40 \mathrm{~Hz}-110 \mathrm{MHz}$ at room temperature. The higher frequency response corresponding to the small arc is attributed to the contribution of semiconducting grains, and the large semi-circular arc at lower frequency range to the insulating grain boundaries $[7,25]$. This result indicates that all samples are electrically heterogeneous consisting of semiconducting grains and insulating grain boundaries. Therefore, the giant dielectric permittivity in $\mathrm{Y}_{2 / 3-x} \mathrm{La}_{x} \mathrm{Cu}_{3} \mathrm{Ti}_{4} \mathrm{O}_{12}$ can be explained by the IBLC model. The grain boundary resistance $\left(R_{g b}\right)$ and grain resistance $\left(R_{g}\right)$ as functions of the $\mathrm{Nd}$ substitution content are shown in Fig. 4(b). It is evident as shown in Fig. 4(b) that Nd doping could strongly enhance the $R_{g b}$ value. The increased $R_{g b}$ value closely correlates with the refined grain size after $\mathrm{Nd}$ doping shown in Fig. 2, which will depress the total electrical conductivity of samples and realize the decrease of low-frequency dielectric loss as shown in Fig. 3(b). Generally, total energy loss in dielectric materials is the sum of loss due to the dielectric relaxation process and loss due to DC conductivity [27]. The total loss tangent can be expressed as [28],

$$
\tan \delta=\frac{\omega^{2} \varepsilon_{0} \tau\left(\varepsilon_{s}^{\prime}-\varepsilon_{\infty}^{\prime}\right)+\left(1+\omega^{2} \tau^{2}\right) \sigma_{d c}}{\omega \varepsilon_{0}\left(\varepsilon_{s}^{\prime}+\varepsilon_{\infty}^{\prime} \omega^{2} \tau^{2}\right)},
$$

where $\varepsilon^{\prime}$ s and $\varepsilon_{\infty}^{\prime}$ are, respectively, the static and high frequency limits of dielectric permittivity, $\tau$ is relaxation time, $\varepsilon_{0}$ is permittivity of free space, and $\sigma_{\mathrm{dc}}$ is DC conductivity. At low frequencies, $\omega \tau<<1$, Eq. (1) is estimated to be 
$\tan \delta \approx \frac{\sigma_{d c}}{\omega \varepsilon_{0} \varepsilon_{s}^{\prime}}$

According to the IBLC structure of YCTO ceramics, the DC conductivity can be approximately expressed as

$$
\sigma_{d c}=1 / C_{0} R_{g b}
$$

Therefore, the low-frequency dielectric loss in YCTO based ceramics could be expressed as

$$
\tan \delta \approx \frac{1}{\omega C_{0} \varepsilon_{0} \varepsilon_{s}^{\prime} R_{g b}},
$$

In other words, the the highest resistance of grain boundary is corresponded to the lowest low-frequency dielectric loss. It also can be seen in Fig. 4(b) that the $R_{g}$ value is slightly increased after $\mathrm{Nd}$ doing. It is widely accepted that without the semiconducting grains there would be no high dielectric constant in ACTO materials [7]. Therefore, the slight decrease in $R_{g}$ value will give rise to a weak decrease in low-frequency high permittivity plateau, which has been clearly observed in Fig.3(a).

Figs. 5 and 6 exhibit the temperature dependences of dielectric constant $\varepsilon^{\prime}$ and dielectric loss tan $\delta$ for $\mathrm{Y}_{2 / 3-x} \mathrm{Nd}_{x} \mathrm{Cu}_{3} \mathrm{Ti}_{4} \mathrm{O}_{12}$ ceramics measured at various frequencies. It is clearly seen in Fig. 5 that all the ceramics exhibit two obvious step-like increases of dielectric constant at low frequency with increasing measuring temperature. The step-like increases observed around 150 and $300{ }^{\circ} \mathrm{C}$ were indicated as Step 1 and 2 in Fig. 5, respectively. With increasing measuring frequency, the step-like increases of dielectric constant shift to higher temperatures and suppress in amplitude with increasing frequency. This indicates that there exists at least one Debye-like relaxation 
behavior in $\mathrm{Y}_{2 / 3-x} \mathrm{Nd}_{x} \mathrm{Cu}_{3} \mathrm{Ti}_{4} \mathrm{O}_{12}$ ceramics. Furthermore, compared with pure YCTO ceramics, the intensity of dielectric relaxation is weakened obviously at $x=0.03$ and 0.06 , suggesting that proper amount of $\mathrm{Nd}$ doping is of great benefit to the improvement of the temperature stability of dielectric constant. In general, one Debye-like relaxation is accompanied by the appearance of the dielectric loss peak (or hump) in $\tan \delta-T$ plot. As shown in Fig. 6, two dielectric loss humps are observed around 150 and $300{ }^{\circ} \mathrm{C}$ for pure YCTO ceramics, respectively. After Nd doping, the high temperature dielectric loss hump disappears and only low temperature dielectric loss humps occur. The dielectric loss hump observed around 150 and $300{ }^{\circ} \mathrm{C}$ are indicated as Hump 1 and Hump 2, respectively. It can also be seen that by $\mathrm{Nd}$ doping, the low-temperature dielectric loss humps (corresponding to Step 1) are strongly weakened, which corresponds to the depressed intensity of dielectric relaxation in Fig. 5. The disappearance of high-temperature dielectric loss hump might be due to higher conductivity at high temperature and the expected dielectric loss peak may be concealed by high conductivity [29].

In order to further reveal the electric response of grain boundary in $\mathrm{Nd}$-doped YCTO ceramics, the ac conductivity $\sigma^{\prime}$ data have been collected to obtain comprehensive electric details. Fig. 7 displays the frequency dependences of ac conductivity $\sigma^{\prime}$ for $\mathrm{Y}_{2 / 3-x} \mathrm{Nd}_{x} \mathrm{Cu}_{3} \mathrm{Ti}_{4} \mathrm{O}_{12}$ ceramics measured at various temperatures. For all samples, at higher temperatures, the frequency-independent conductivity plateaus are observed in a lower frequency range in the conductivity plots and extends to higher frequencies with the increase of temperature. The high temperature electrical 
conduction behaviors obey the universal power law by Jonscher [30],

$$
\sigma^{\prime}=\sigma_{d c}+\sigma_{0} \omega^{s}
$$

where $\sigma_{d c}$ is the low-frequency limit of the conductivity, $\sigma_{0}$ is a constant, $\omega$ is the angular frequency, and the exponent $s$ is smaller than 1. Eq. (5) is a common feature for all amorphous semiconductors and some other disordered systems. It is typical of thermal assisted tunneling between localized states [31]. Based on the IBLC effect, this low-frequency plateaus observed at higher temperatures could be approximately ascribed to the contribution of the electrical conduction in insulating grain boundaries. The fitted parameter $\sigma_{d c}$ according to Eq. 5 follows the Arrhenius law,

$$
\sigma_{d c}=T^{-1} \sigma_{0} \exp \left(-\frac{E_{c o n d}}{K_{B} T}\right)
$$

where $\sigma_{0}$ is the pre-exponential term, $E_{\text {cond }}$ is the conduction activation energy, and $K_{\mathrm{B}}$ is the Boltzmann constant. As shown in Fig. 8, for all $\mathrm{Y}_{2 / 3-x} \mathrm{Nd}_{x} \mathrm{Cu}_{3} \mathrm{Ti}_{4} \mathrm{O}_{12}$ ceramics, a good linear relationship between $\ln \left(\sigma_{\mathrm{dc}} T\right)$ and $1 / T$ is satisfied. The conduction activation energies of $\mathrm{Y}_{2 / 3-x} \mathrm{Nd}_{x} \mathrm{Cu}_{3} \mathrm{Ti}_{4} \mathrm{O}_{12}$ ceramics with $x=0.00,0.03,0.06,0.09$, and 0.12 are $0.60,0.63,0.65,0.66$ and $0.65 \mathrm{eV}$, respectively. It is obvious that the activation energies for electrical conduction in grain boundaries are slightly influenced by $\mathrm{Nd}$ doping compared with the dramatically decreased low-frequency dielectric loss and suppressed grain size, which means that the Nd doping ions had a main effect on the geometric factor, but not for the intrinsic factor of grain boundary. In other word, the decreased low-frequency dielectric loss should be correlated to the increase of grain boundary density rather than the enhanced resistivity of individual grain boundary $[6,16]$. 
Electric modulus formalism is an very useful tool to determine, analyze and interpret the dynamical aspects of electrical transport phenomena i.e. parameters such as carrier/ion hopping rate, conductivity relaxation time etc. The electric modulus can be derived from the following equation:

$$
M *(\omega)=j \omega C_{0} Z *(\omega)=1 / \varepsilon^{*}(\omega)
$$

where $C_{0}$ is the vacuum capacitance of the cell. Based on the IBLC structure, the real and imaginary part of electric modulus could separately expressed as

$$
\begin{aligned}
& \mathbf{M}^{\prime}=R_{g}\left[\frac{\omega^{2} R_{g} C_{g}}{1+\left(\omega R_{g} C_{g}\right)^{2}}\right]+R_{g b}\left[\frac{\omega^{2} R_{g b} C_{g b}}{1+\left(\omega R_{g b} C_{g b}\right)^{2}}\right] \\
& \mathbf{M}^{\prime}=\frac{C_{0}}{C_{g}}\left[\frac{\omega R_{g} C_{g}}{1+\left(\omega R_{g} C_{g}\right)^{2}}\right]+\frac{C_{0}}{C_{g b}}\left[\frac{\omega R_{g b} C_{g b}}{1+\left(\omega R_{g b} C_{g b}\right)^{2}}\right],
\end{aligned}
$$

where $R_{g}$ and $R_{g b}$ are the grain resistance and grain boundary resistance, respectively. $C_{g}$ and $C_{g b}$ are the grain capacitance and grain boundary capacitance,respectively.

Fig. 9 shows the frequency dependence of the real part of the electric modulus $M^{\prime}$ for $\mathrm{Y}_{2 / 3-x} \mathrm{Nd}_{x} \mathrm{Cu}_{3} \mathrm{Ti}_{4} \mathrm{O}_{12}$ ceramics measured at different temperatures. As can be seen in Fig. 9, all samples show one obvious step-like increase in $M^{\prime}(\omega)$ in the measurement frequency range, and the step-like increase gradually shifts to high frequency with increasing temperature. Correspondingly, the frequency dependence of the imaginary part of the electric modulus $M^{\prime \prime}$ for $\mathrm{Y}_{2 / 3-x} \mathrm{Nd}_{x} \mathrm{Cu}_{3} \mathrm{Ti}_{4} \mathrm{O}_{12}$ ceramics measured are given in Fig. 10. For all samples, $M^{\prime \prime}(\omega)$ plots exhibit the electric modulus peak when the measuring temperature is higher than $90{ }^{\circ} \mathrm{C}$ and the electric modulus peaks shift toward higher frequencies as the measuring temperatures increases. The peaks appearing in the pattern are asymmetric and broadened, which indicates the spread of relaxation with 
a relaxation time constant distribution. Furthermore, high-frequency inclines in the $M^{\prime \prime}(\omega)$ plots are observed when the measuring temperature is lower than $90{ }^{\circ} \mathrm{C}$, and they also shift towards higher frequencies as the measuring temperatures increases. In general, according to IBLC model, each element corresponds to the occurrence of one Debye-relaxation peak in $M^{\prime \prime}(\omega)$ plots. Therefore, combined with the impedance results shown in Fig. 4(a), the observed electric modulus peaks are ascribed to the grain boundary response and the high-frequency inclines in $M^{\prime \prime}(\omega)$ plots are attributed to the grain response. It can also be seen that the amplitudes of the relaxation peaks in $M^{\prime \prime}(\omega)$ plots, which is inversely proportional to the grain boundary capacitance [25], are slightly enhanced by $\mathrm{Nd}$ doping. This suggests that $\mathrm{Nd}$ doping induces a decrease in the grain boundary capacitance and in turn give rise to a decrease in low-frequency dielectric constant plateaus which is mainly derived from grain boundary effect. This result is well consistent with the result obtained from Fig. 3(a).

The frequency of $M^{\prime \prime}$ peak $\left(f_{\max }\right)$ gives the mean value of the relaxation time distribution, $\tau=1 / 2 \pi f_{\max }$. The Arrhenius plot $\left(\ln \left(f_{\max }\right)\right.$ versus $\left.1 / \mathrm{T}\right)$ shown in Fig. 11 exhibits a linear relationship in the whole temperature range. The activation energies for the relaxation process of $\mathrm{Y}_{2 / 3-x} \mathrm{Nd}_{x} \mathrm{Cu}_{3} \mathrm{Ti}_{4} \mathrm{O}_{12}$ ceramics with $x=0.00,0.03,0.06,0.09$, and 0.12 are $0.69,0.67,0.67,0.67$, and $0.70 \mathrm{eV}$, respectively. It is evident that the activation energies for the relaxation process are nearly not changed by $\mathrm{Nd}$ doping. Furthermore, it is interesting to observe that the activation energies for the dielectric relaxation and electrical conduction process of grain boundary present similar value, indicating that same entities are responsible for the electrical conduction and dielectric 
relaxation process of grain boundary. Generally, in oxide materials, high temperature sintering process will generate the single-ionized $\left(V_{O}^{\bullet}\right)$ and doubly-ionized $\left(V_{o}^{\bullet \bullet}\right)$ oxygen vacancies and extra electrons will be introduced [29,32-34]. It is widely reported that the activation energies for doubly-ionized oxygen vacancies are in the range of 0.6-1.2 [35-37]. Therefore, it can be tentatively concluded that the conduction process of grain boundary might be dominated by the thermal excitation of electrons from the second ionization of oxygen vacancies $\left(V_{o}^{\bullet \bullet}\right)$ to the conduction band $[35,36,38]$. Furthermore, the dipoles could be formed by oxygen vacancies with adjacent host ions, which give rise to the dielectric relaxation behavior. 


\section{Conclusion}

Significant decrease in low-frequency dielectric loss of YCTO ceramics was realized by refining the grain size after A-site $\mathrm{Nd}$ doping. When $x=0.06$ and 0.09 , the samples exhibited a relatively low dielectric loss (below 0.050 between 0.3 and $50 \mathrm{kHz}$ ) and high dielectric constant above 11000 over a wide frequency range from $40 \mathrm{~Hz}$ to 100 $\mathrm{kHz}$. The enhanced grain boundary density is of great benefit to increasing the grain boundary resistance and in turn give rise to a lowered low-frequency dielectric loss of YCTO ceramics. Nd doping could depress the intensity of dielectric relaxation and improve the temperature stability of dielectric constant. Besides, based on the dc conductivity and electric modulus results, the grain boundary responses had been clarified By $\mathrm{Nd}$ doping, the activation energies for the electrical conduction and dielectric relaxation behaviors in grain boundaries of YCTO ceramics were obviously enhanced and slightly changed, respectively. The same defect complexity, doubly-ionized oxygen vacancies $V_{O} \ddot{\text {, }}$ contributes to the conduction and relaxation process in grain boundaries of $\mathrm{Y}_{2 / 3-x} \mathrm{Nd}_{x} \mathrm{Cu}_{3} \mathrm{Ti}_{4} \mathrm{O}_{12}$ ceramics. This study will help with the design of materials based on the $\mathrm{Y}_{2 / 3} \mathrm{Cu}_{3} \mathrm{Ti}_{4} \mathrm{O}_{12}$ ceramic, which can have a broad application prospect in electronics. 


\section{Acknowledgment}

This work was supported by National Science Foundation of China (NSFC) (Grant No. 51572163, 51172136 and 51577111), the Natural Key Science Basic Research Plan in Shaanxi Province of China (Grant No. 2015JZ011). 


\section{References}

[1]. C.C. Homes, T. Vogt, S.M. Shapiro, S. Wakimoto, A.P. Ramirez, Optical Response of High Dielectric Constant Perovskite-Related Oxide, Science 293 (2001) 673-676.

[2]. S. Krohns, P. Lunkenheimer, S. Meissner, A. Reller, B. Gleich, A. Rathgeber, T. Gaugler, H. U. Buhl, D. C. Sinclair, A. Loidl, The route to resource-efficient novel materials, Nature Mater. 10 (2011) 899-901.

[3]. W.B. Hu, Y. Liu, R.L. Withers, T.J. Frankcombe, L. Noren, A. Snashall, M. Kitchin, P. Smith, B. Gong, H. Chen, J. Schiemer, F. Brink, J. Wong-Leung, Electron pinned defect-dipoles for high-performance colossal permittivity materials, Nature Mater. 12 (2013) 821-826.

[4]. P.F. Liang, Z.P. Yang, X.L. Chao, Z.H. Liu, Giant dielectric constant and good temperature stability in $\mathrm{Y}_{2 / 3} \mathrm{Cu}_{3} \mathrm{Ti}_{4} \mathrm{O}_{12}$ ceramics, J. Am. Ceram. Soc. 95 (2012) $2218-2225$.

[5]. S. Vangchangyia, E. Swatsitang, P. Thongbai, S. Pinitsoontorn, T. Yamwong, S. Maensiri, V. Amornkitbamrung, P. Chindaprasirt, Very low loss tangent and high dielectric permittivity in pure- $\mathrm{CaCu}_{3} \mathrm{Ti}_{4} \mathrm{O}_{12}$ ceramics prepared by a modified sol-gel process, J. Am. Ceram. Soc. 95 (2012) 1497-1500.

[6]. J. Boonlakhorn, B. Putasaeng, P. Kidkhunthod, P. Thongbai, Improved dielectric properties of $(\mathrm{Y}+\mathrm{Mg})$ co-doped $\mathrm{CaCu}_{3} \mathrm{Ti}_{4} \mathrm{O}_{12}$ ceramics by controlling geometric and intrinsic properties of grain boundaries, Mater. Design 92 (2016) 494-498.

[7]. T.B. Adams, D.C. Sinclair, A.R. West, Giant barrier layer capacitance effects in $\mathrm{CaCu}_{3} \mathrm{Ti}_{4} \mathrm{O}_{12}$ ceramics, Adv. Mater. 14 (2002) 1321-1323. 
[8]. T.B. Adams, D.C. Sinclair, A.R. West, Influence of processing conditions on the electrical properties of $\mathrm{CaCu}_{3} \mathrm{Ti}_{4} \mathrm{O}_{12}$ ceramics, J. Am. Ceram. Soc. 89 (2006) $3129-3135$.

[9]. R. Schmidt, M.C. Stennett, N.C. Hyatt, J. Pokorny, J. Prado-Gonjal, M. Li, D.C. Sinclair, Effects of sintering temperature on the internal barrier layer capacitor (IBLC) structure in $\mathrm{CaCu}_{3} \mathrm{Ti}_{4} \mathrm{O}_{12}$ (CCTO) ceramics, J. Eur. Ceram. Soc. 32 (2012) 3313-3323. [10]. Y.H. Lin, J. Cai, M. Li, C.W. Nan, J. He, High dielectric and nonlinear electrical behaviors in $\mathrm{TiO}_{2}$-rich $\mathrm{CaCu}_{3} \mathrm{Ti}_{4} \mathrm{O}_{12}$ ceramics, Appl. Phys. Lett. 88 (2006) 172902.

[11]. S.F. Shao, J.L. Zhang, P. Zheng, C.L. Wang, J.C. Li, M.L. Zhao, High permittivity and low dielectric loss in ceramics with the nominal compositions of $\mathrm{CaCu}_{3-\mathrm{x}} \mathrm{La}_{2 \times / 3} \mathrm{Ti}_{4} \mathrm{O}_{12}$, Appl. Phys. Lett. 91 (2007) 042905.

[12] J. Boonlakhorn, P. Kidkhunthod, B. Putasaeng, T. Yamwong, P. Thongbai, S. Maensiri, Effects of Y doping ions on microstructure, dielectric response, and electrical properties of $\mathrm{Ca}_{1-3 \times / 2} \mathrm{Y}_{\mathrm{x}} \mathrm{Cu}_{3} \mathrm{Ti}_{4} \mathrm{O}_{12}$ ceramics, J. Mater. Sci. Mater. Electron. 26 (2015) $2329-2337$.

[13]. F.C. Luo, J.L. He, J. Hu, Electric and Dielectric Behaviors of Y-Doped Calcium Copper Titanate, J. Am. Ceram. Soc. 93 (2010) 3043-3045.

[14]. P.F. Liang, X.L. Chao, F. Wang, Z.Q. Liu, Z.P. Yang, The Lowered Dielectric Loss and Grain-Boundary Effects in La-doped $\mathrm{Y}_{2 / 3} \mathrm{Cu}_{3} \mathrm{Ti}_{4} \mathrm{O}_{12}$ Ceramics, J. Am. Ceram. Soc. 96 (2013) 3883-3890.

[15]. Z. Yang, L. Zhang, X. Chao, L. Xiong, J. Liu, High permittivity and low dielectric loss of the $\mathrm{Ca}_{1-\mathrm{x}} \mathrm{Sr}_{\mathrm{x}} \mathrm{Cu}_{3} \mathrm{Ti}_{4} \mathrm{O}_{12}$ ceramics, J. Alloys Compd. 509 (2011) 8716-8719. 
[16]. J. Jumpatam, B. Putasaeng, T. Yamwong, P. Thongbai, S. Maensiri, A novel strategy to enhance dielectric performance and non-Ohmic properties in $\mathrm{Ca}_{2} \mathrm{Cu}_{2-\mathrm{x}} \mathrm{Mg}_{\mathrm{x}} \mathrm{Ti}_{4} \mathrm{O}_{12}$, J. Eur. Ceram. Soc. 34 (2014) 2941-2950.

[17]. L. Ni, X.M. Chen, Enhanced giant dielectric response in Mg-substituted $\mathrm{CaCu}_{3} \mathrm{Ti}_{4} \mathrm{O}_{12}$ ceramics, Solid State Commun. 149 (2009) 379-383.

[18]. P.F. Liang, X.L. Chao, Z.P. Yang, Low dielectric loss, dielectric response, and conduction behavior in Na-doped $\mathrm{Y}_{2 / 3} \mathrm{Cu}_{3} \mathrm{Ti}_{4} \mathrm{O}_{12}$ ceramics, J. Appl. Phys. 116 (2014) 044101.

[19]. P.F. Liang, X.L. Chao, Z.P. Yang, Dielectric response, impedance spectroscopy and scaling behavior of $\mathrm{K}$-doped $\mathrm{Y}_{2 / 3} \mathrm{Cu}_{3} \mathrm{Ti}_{4} \mathrm{O}_{12}$ ceramics, Mater. Chem. Phys. 167 (2015) $103-111$.

[20]. X.J. Chou, J.W. Zhai, H.T. Jiang, X. Yao, Dielectric properties and relaxor behavior of rare-earth ( $\mathrm{La}, \mathrm{Sm}, \mathrm{Eu}, \mathrm{Dy}, \mathrm{Y})$ substituted barium zirconium titanate ceramics, J. Appl. Phys. 102 (2007) 084106.

[21]. J. Boonlakhorn, P. Thongbai, B. Putasaeng, T. Yamwong, S. Maensiri, Very high-performance dielectric properties of $\mathrm{Ca}_{1-3 \times / 2} \mathrm{Yb}_{\mathrm{x}} \mathrm{Cu}_{3} \mathrm{Ti}_{4} \mathrm{O}_{12}$ ceramics, J. Alloys Compd. 612 (2014) 103-109.

[22]. J.W. Cahn, Acta Metall. 10 (1962) 789-798.

[23] W.M. White, Geochemistry, first ed., Wiley-Blackwell, Oxford, 2013.

[24] M.N. Rahamann, Ceramic Processing and Sintering, second ed., Marcel Dekker, New York, 2003.

[25]. D.C. Sinclair, A.R. West, Impedance and modulus spectroscopy of semiconducting 
$\mathrm{BaTiO}_{3}$ showing positive temperature coefficient of resistance, J. Appl. Phys. 66 (1989) 3850.

[26]. J.T.S. Irvine, D.C. Sinclair, A.R. West, Electroceramics: characterization by impedance spectroscopy, Adv. Mater. 2 (1990) 132-138.

[27]. P. Lunkenheimer, S. Krohns, R. Fichtl, S. G. Ebbinghaus, A. Reller, A. Loidl, Colossal Dielectric Constants in Transition-Metal Oxides, Eur. Phys. J. Spec. Top. 180 (2010) 61-89.

[28]. K.C. Kao, Dielectric Phenomena in Solids, 1st edition, Elsevier, California, 2004.

[29]. C.C. Wang, M.N. Zhang, K.B. Xu, G.J. Wang, Origin of high-temperature relaxor-like behavior in $\mathrm{CaCu}_{3} \mathrm{Ti}_{4} \mathrm{O}_{12}$, J. Appl. Phys. 112 (2012) 034109.

[30]. A.K. Jonscher, The 'universal' dielectric response, Nature 267 (1977) 673-679.

[31]. L. Zhang, Z.J. Tang, Polaron relaxation and variable-range-hopping conductivity in the giant-dielectric-constant material $\mathrm{CaCu}_{3} \mathrm{Ti}_{4} \mathrm{O}_{12}$, Phys. Rev. B 70 (2004) 174306. [32]. M.A. Ramírez, P.R. Bueno, J.A. Varela, E. Longo, Non-Ohmic and dielectric properties of a $\mathrm{Ca}_{2} \mathrm{Cu}_{2} \mathrm{Ti}_{4} \mathrm{O}_{12}$ polycrystalline system, Appl. Phys. Lett. 89 (2006) 212102

[33]. C. C. Wang, Y. M. Cui, G. L. Xie, C. P. Chen, and L. W. Zhang, Phase separation in $\mathrm{La}_{2} \mathrm{CuO}_{4+y}$ ceramics probed by dielectric measurements, Phys. Rev. B 72 (2005) 064513.

[34]. C.C. Wang, L.W. Zhang, Oxygen-vacancy-related dielectric anomaly in $\mathrm{CaCu}_{3} \mathrm{Ti}_{4} \mathrm{O}_{12}$ : Post-sintering annealing studies, Phys. Rev. B 74 (2006) 024106. 
[35]. C. Ang, Z. Yu, L.E. Cross, Oxygen-vacancy-related low-frequency dielectric relaxation and electrical conduction in $\mathrm{Bi}: \mathrm{SrTiO}_{3}$, Phys. Rev. B 62 (2000) 228.

[36]. H.S. Shulman, D. Damjanovic, N. Setter, Niobium Doping and Dielectric Anomalies in Bismuth Titanate, J. Am. Ceram. Soc. 83 (2000) 528.

[37]. O. Bidault, P. Goux, M. Kchikech, M. Belkaoumi, M. Maglione, Space-charge relaxation in perovskites, Phys. Rev. B 49 (1994) 7868.

[38]. L.N. Liu, C.C. Wang, C.M. Lei, T. Li, G.J. Wang, X.H. Sun, J. Wang, S.G. Huang, Y.D. Li, H. Wang, Relaxor- and phase-transition-like behaviors in $\mathrm{ZnO}$ single crystals at high temperatures, Appl. Phys. Lett. 102 (2013) 112907. 


\section{Figure captions}

Fig.1. XRD patterns of the as-sintered $\mathrm{Y}_{2 / 3-x} \mathrm{Nd}_{x} \mathrm{Cu}_{3} \mathrm{Ti}_{4} \mathrm{O}_{12}(x=0.00,0.03,0.06,0.09$, and 0.12 ) ceramics.

Fig.2. SEM images of the surfaces of $\mathrm{Y}_{2 / 3-x} \mathrm{Nd}_{x} \mathrm{Cu}_{3} \mathrm{Ti}_{4} \mathrm{O}_{12}$ ceramics: (a) $x=0.00$, (b) $x=$ 0.03 , (c) $x=0.06$, (d) $x=0.09$, and (e) $x=0.12$, respectively.

Fig.3. (a) Frequency dependence of the real part $\varepsilon^{\prime}$ of the dielectric constant, and the inset shows the expanded view of low-frequency dielectric constant of $\mathrm{Y}_{2 / 3-x} \mathrm{Nd}_{x} \mathrm{Cu}_{3} \mathrm{Ti}_{4} \mathrm{O}_{12}$ ceramics. (b) Frequency dependence of the dielectric loss $\tan \delta$, and the inset shows the expanded view of low-frequency dielectric loss of $\mathrm{Y}_{2 / 3-x} \mathrm{Nd}_{x} \mathrm{Cu}_{3} \mathrm{Ti}_{4} \mathrm{O}_{12}$ ceramics.

Fig.4 (a) Complex impedance plots of $\mathrm{Y}_{2 / 3-x} \mathrm{Nd}_{x} \mathrm{Cu}_{3} \mathrm{Ti}_{4} \mathrm{O}_{12}$ ceramics, and the inset exhibits an expanded view of high frequency data close to the origin. (b) Grain boundary resistance $\left(R_{g b}\right)$ and grain resistance $\left(R_{g}\right)$ as functions of the Nd substitution content.

Fig.5. Temperature dependences of dielectric constant $\varepsilon^{\prime}$ for $\mathrm{Y}_{2 / 3-x} \mathrm{Nd}_{x} \mathrm{Cu}_{3} \mathrm{Ti}_{4} \mathrm{O}_{12}$ ceramics measured at various frequencies: (a) $x=0.00$, (b) $x=0.03$, (c) $x=0.06$, (d) $x=$ 0.09 , and (e) $x=0.12$, respectively.

Fig.6. Temperature dependences of dielectric loss $\tan \delta$ for $\mathrm{Y}_{2 / 3-} \mathrm{Nd}_{x} \mathrm{Cu}_{3} \mathrm{Ti}_{4} \mathrm{O}_{12}$ ceramics measured at various frequencies: (a) $x=0.00$, (b) $x=0.03$, (c) $x=0.06$, (d) $x=0.09$, and (e) $x=0.12$, respectively.

Fig.7. Frequency dependences of ac conductivity $\sigma^{\prime}$ for $\mathrm{Y}_{2 / 3-x} \mathrm{Nd}_{x} \mathrm{Cu}_{3} \mathrm{Ti}_{4} \mathrm{O}_{12}$ ceramics measured at various temperatures: (a) $x=0.00$, (b) $x=0.03$, (c) $x=0.06$, (d) $x=0.09$, 
and (e) $x=0.12$, respectively.

Fig.8. Arrhenius plots of $\ln \sigma_{\mathrm{dc}} T$ vs $1000 / \mathrm{T}$ for electrical conductivity of $\mathrm{Y}_{2 / 3-x} \mathrm{Nd}_{x} \mathrm{Cu}_{3} \mathrm{Ti}_{4} \mathrm{O}_{12}$ ceramics: (a) $x=0.00$, (b) $x=0.03$, (c) $x=0.06$, (d) $x=0.09$, and (e) $x=0.12$, respectively.

Fig.9. Frequency dependence of the real part $M^{\prime}$ of electric modulus for $\mathrm{Y}_{2 / 3-x} \mathrm{Nd}_{x} \mathrm{Cu}_{3} \mathrm{Ti}_{4} \mathrm{O}_{12}$ ceramics measured at various temperatures: (a) $x=0.00$, (b) $x=$ 0.03 , (c) $x=0.06$, (d) $x=0.09$, and (e) $x=0.12$, respectively.

Fig.10. Frequency dependence of the imaginary part $M^{\prime \prime}$ of electric modulus for $\mathrm{Y}_{2 / 3-x} \mathrm{Nd}_{x} \mathrm{Cu}_{3} \mathrm{Ti}_{4} \mathrm{O}_{12}$ ceramics measured at various temperatures: (a) $x=0.00$, (b) $x=$ 0.03 , (c) $x=0.06$, (d) $x=0.09$, and (e) $x=0.12$, respectively.

Fig.11. Arrhenius relations of $\ln f_{\max }$ vs $1000 / \mathrm{T}$ for the relaxation process of $\mathrm{Y}_{2 / 3-x} \mathrm{Nd}_{x} \mathrm{Cu}_{3} \mathrm{Ti}_{4} \mathrm{O}_{12}$ ceramics: (a) $x=0.00$, (b) $x=0.03$, (c) $x=0.06$, (d) $x=0.09$, and (e) $x=0.12$, respectively. 

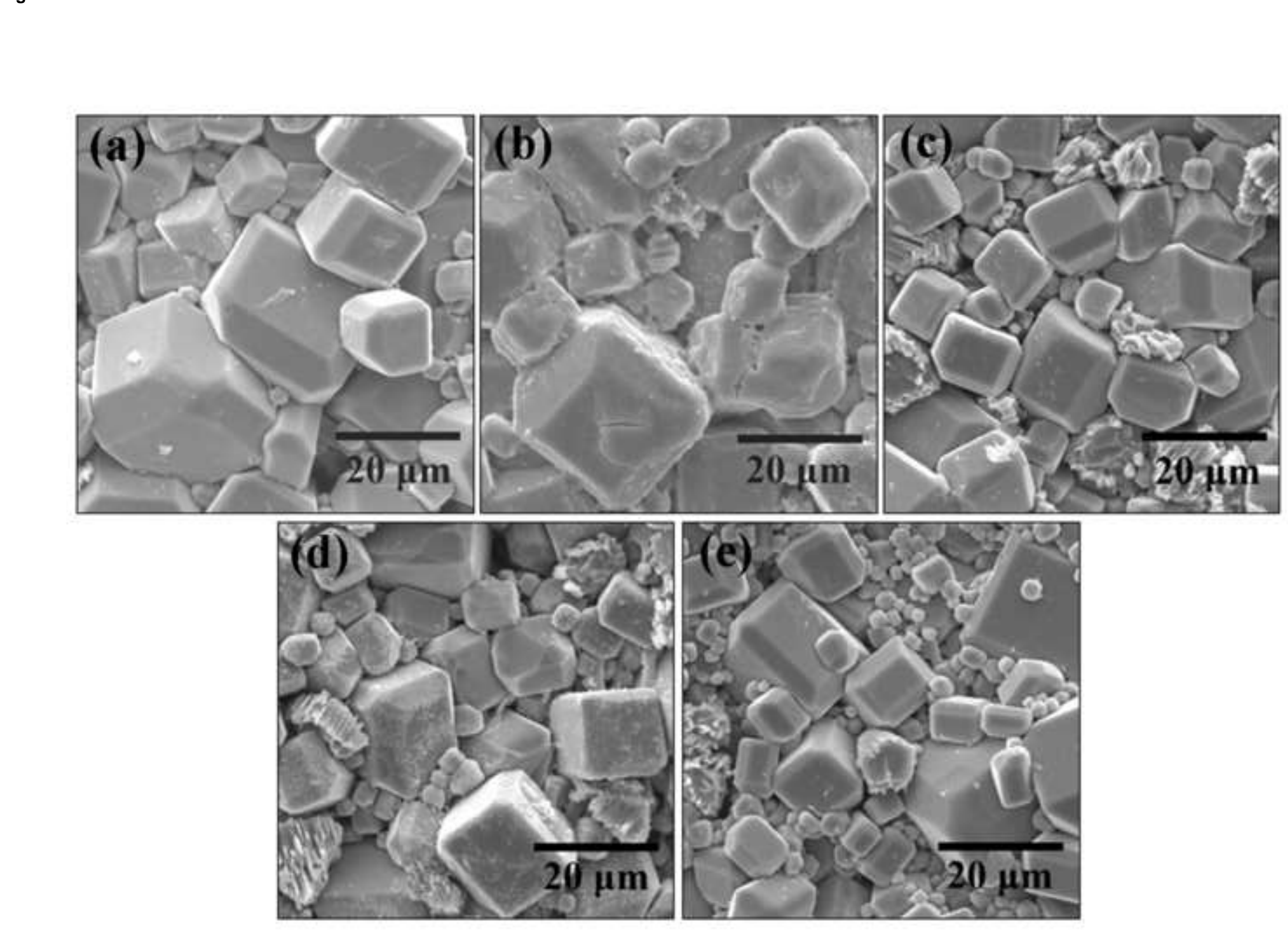
Figure 3

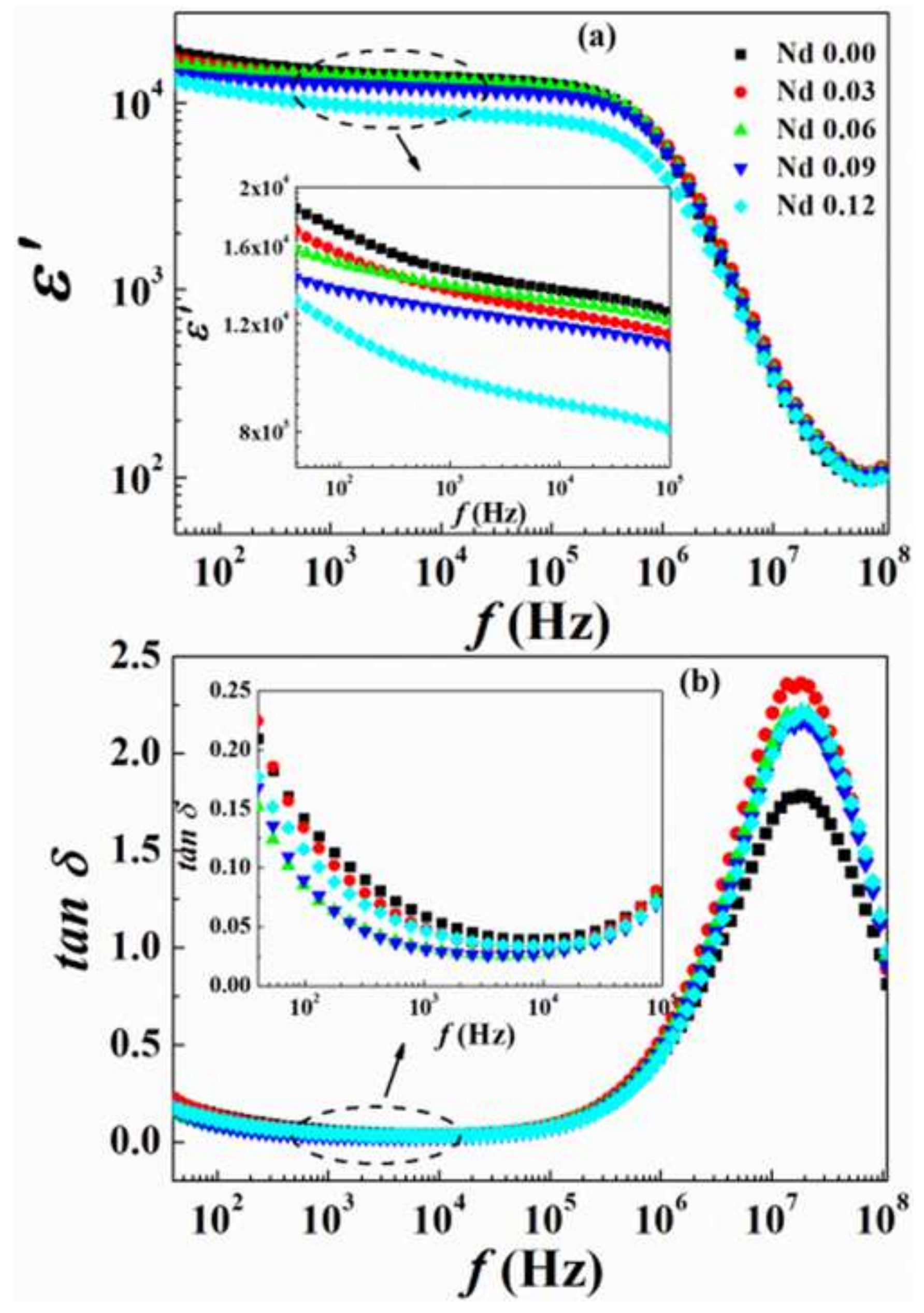




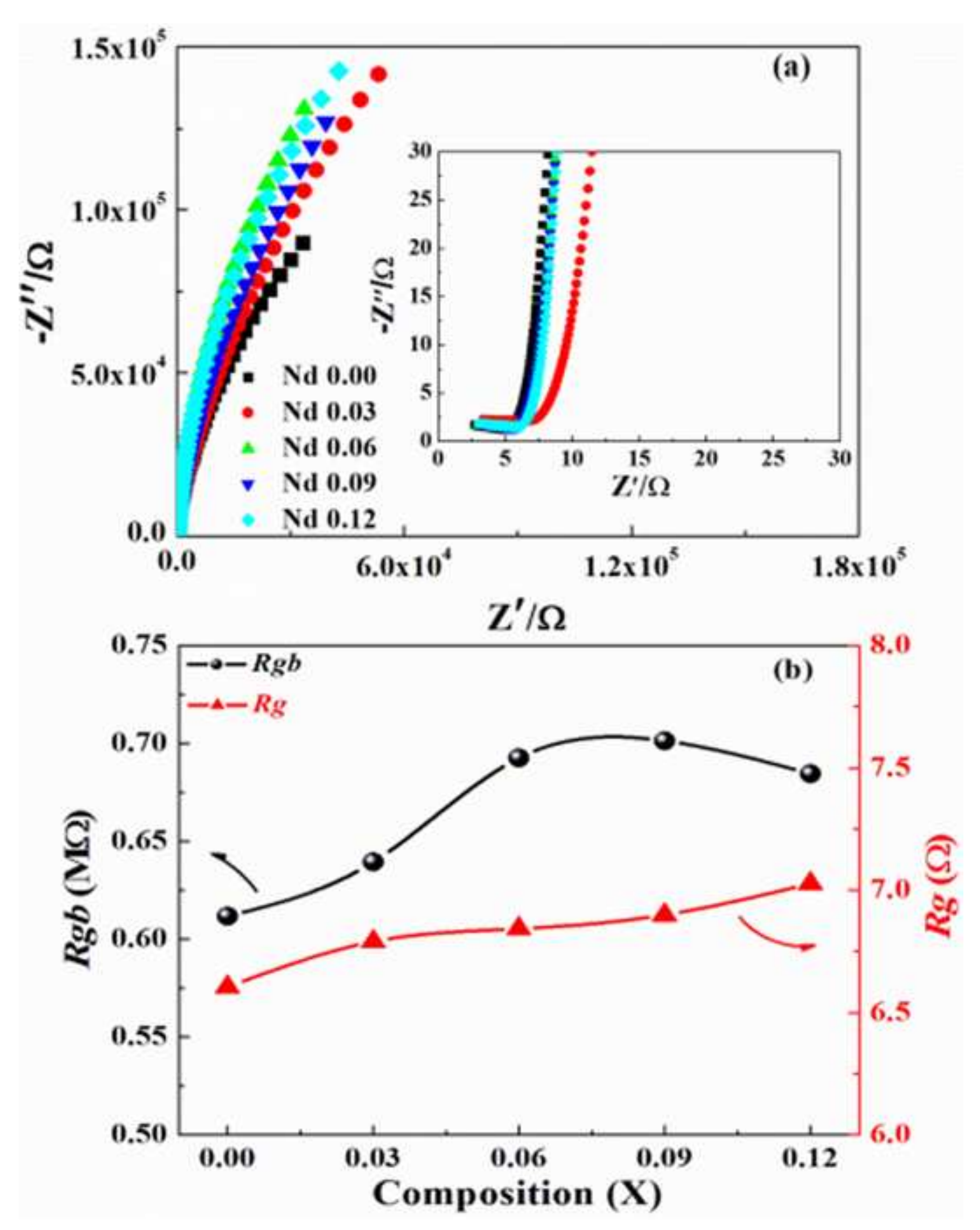

Figure 4

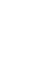



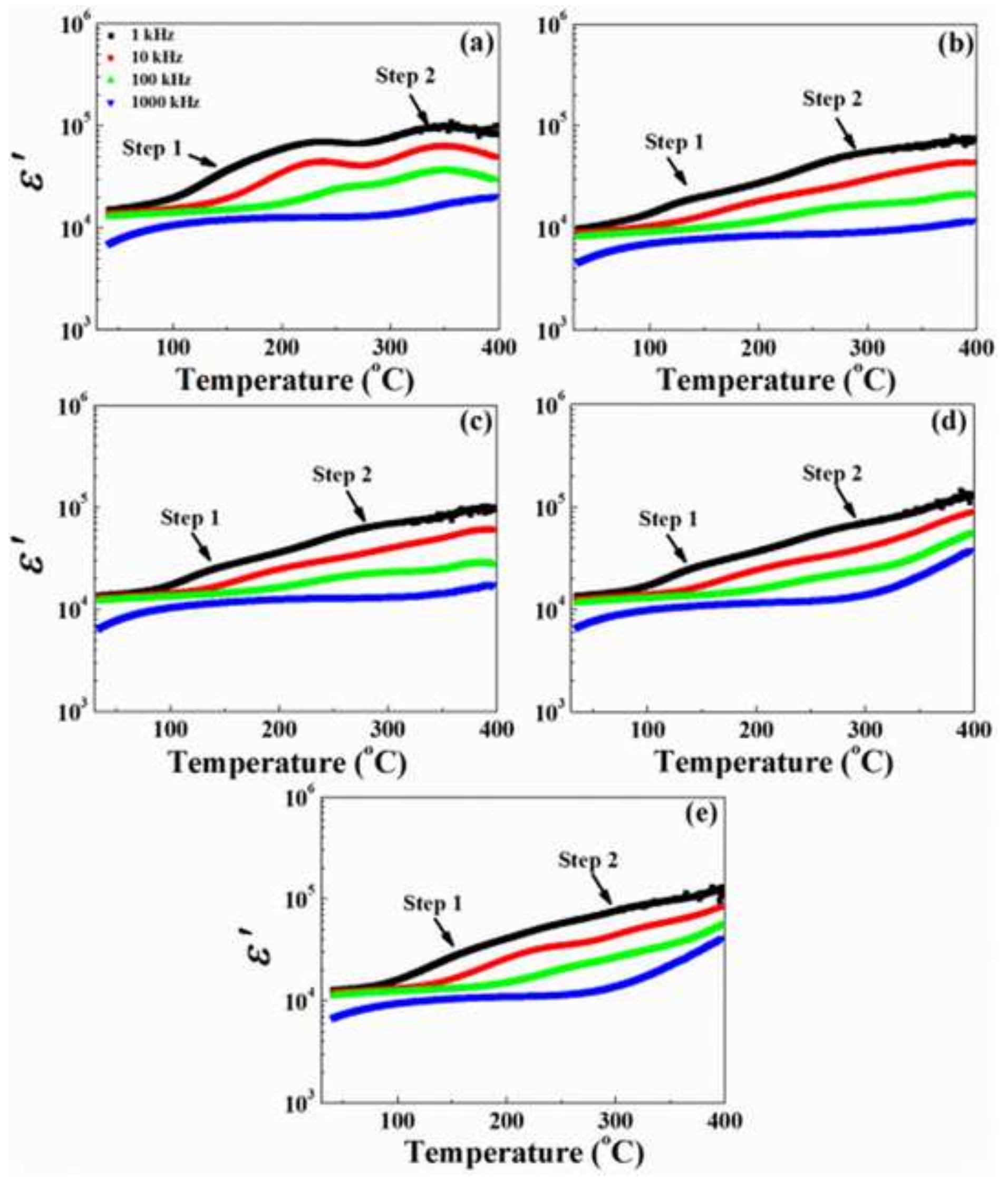

Temperature $\left({ }^{\circ} \mathrm{C}\right)$ 

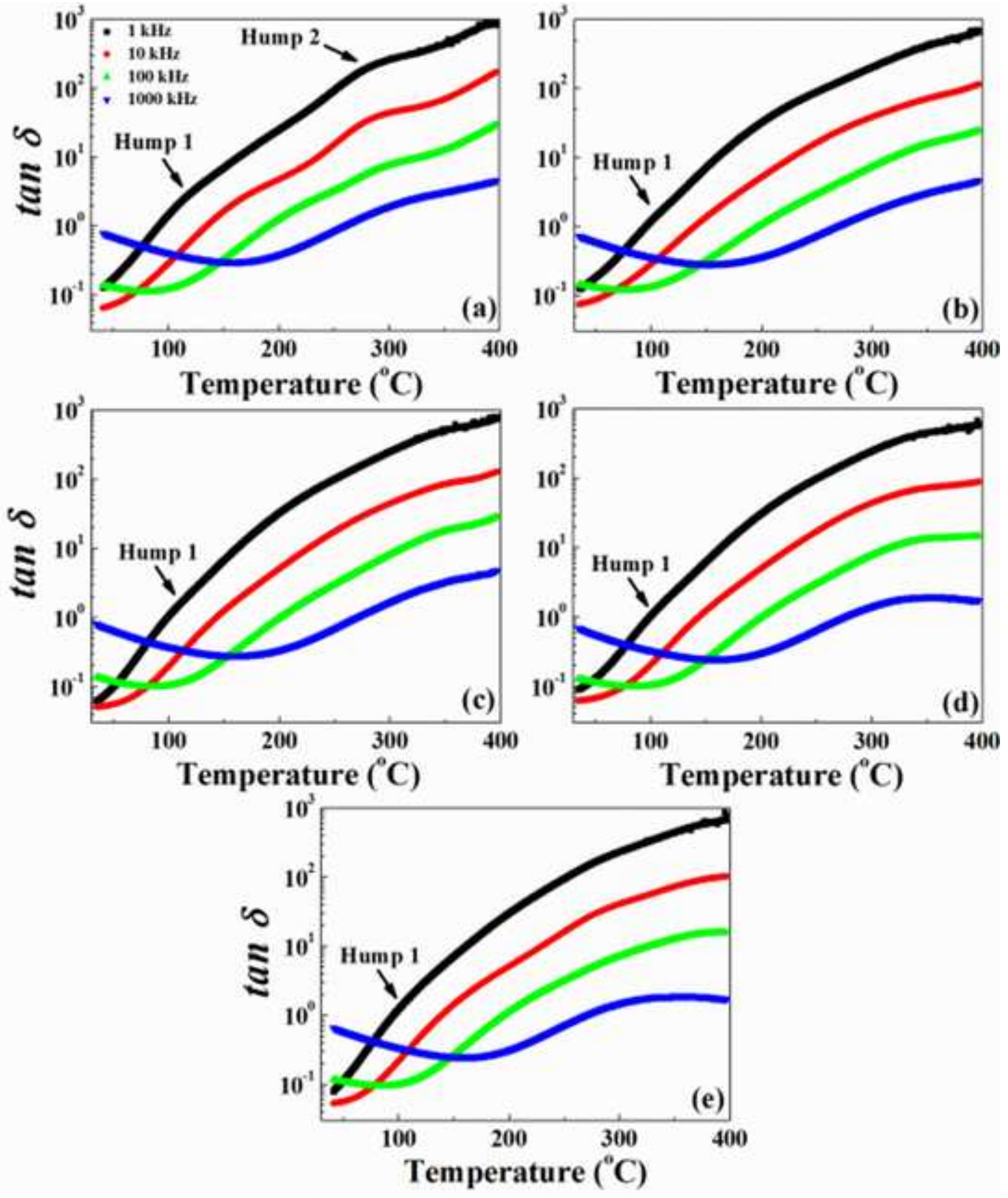

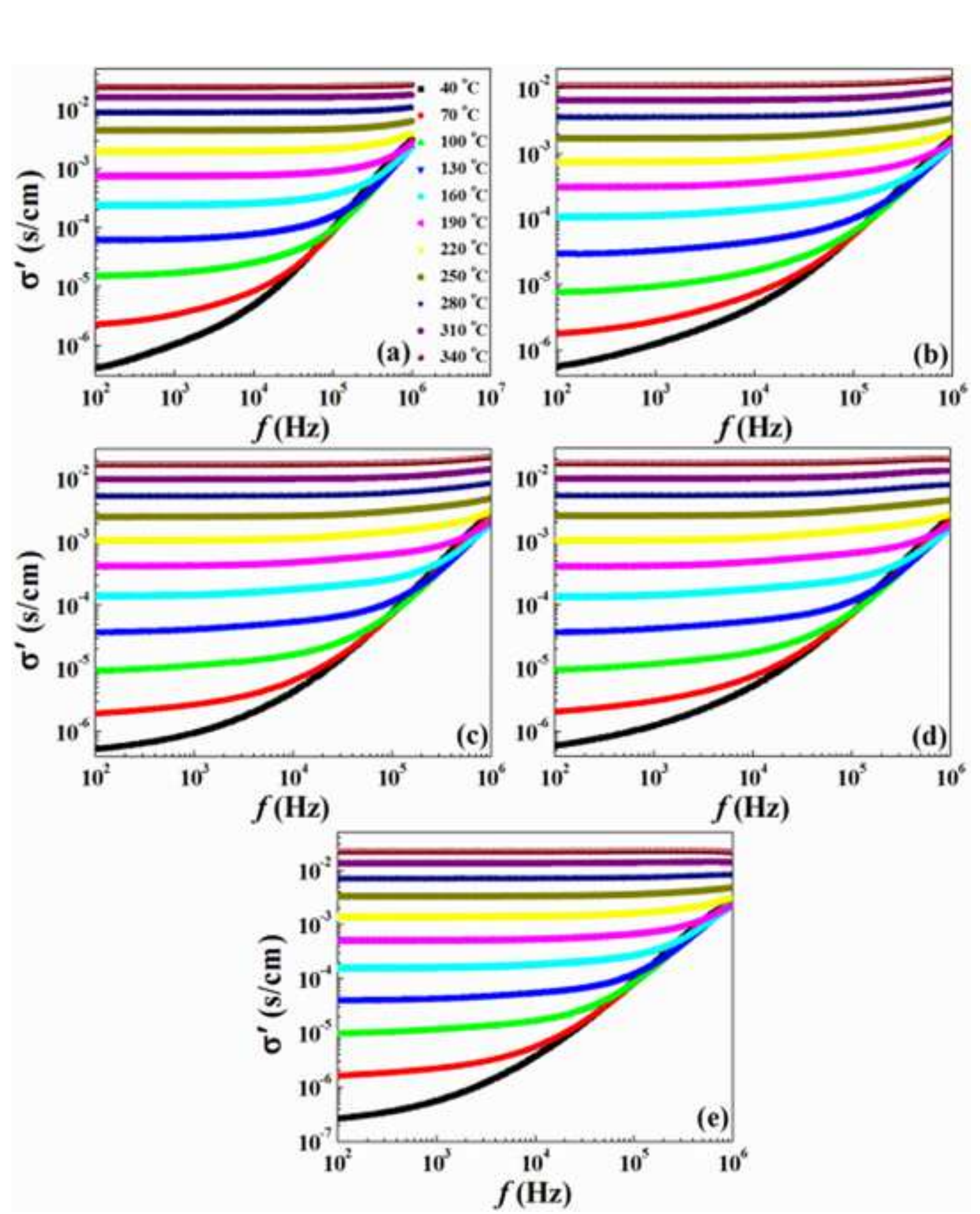

Figure

\section{7}

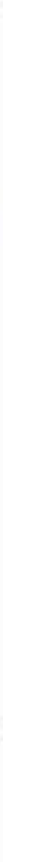

\section{Figure}

oydo 

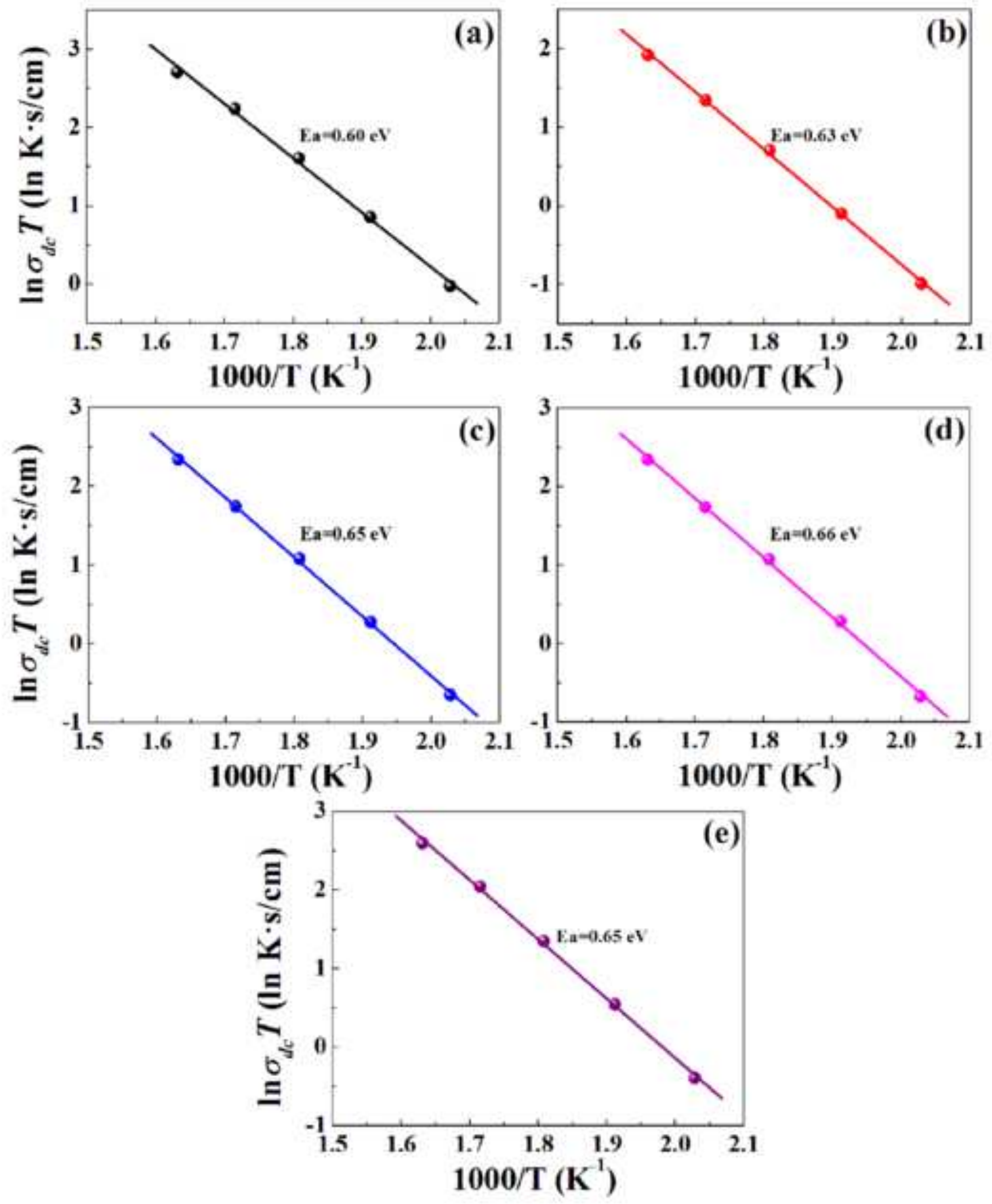

Figure 8

(e) $1000 / \mathrm{T}_{\left(\mathrm{K}^{-1}\right)}$ 

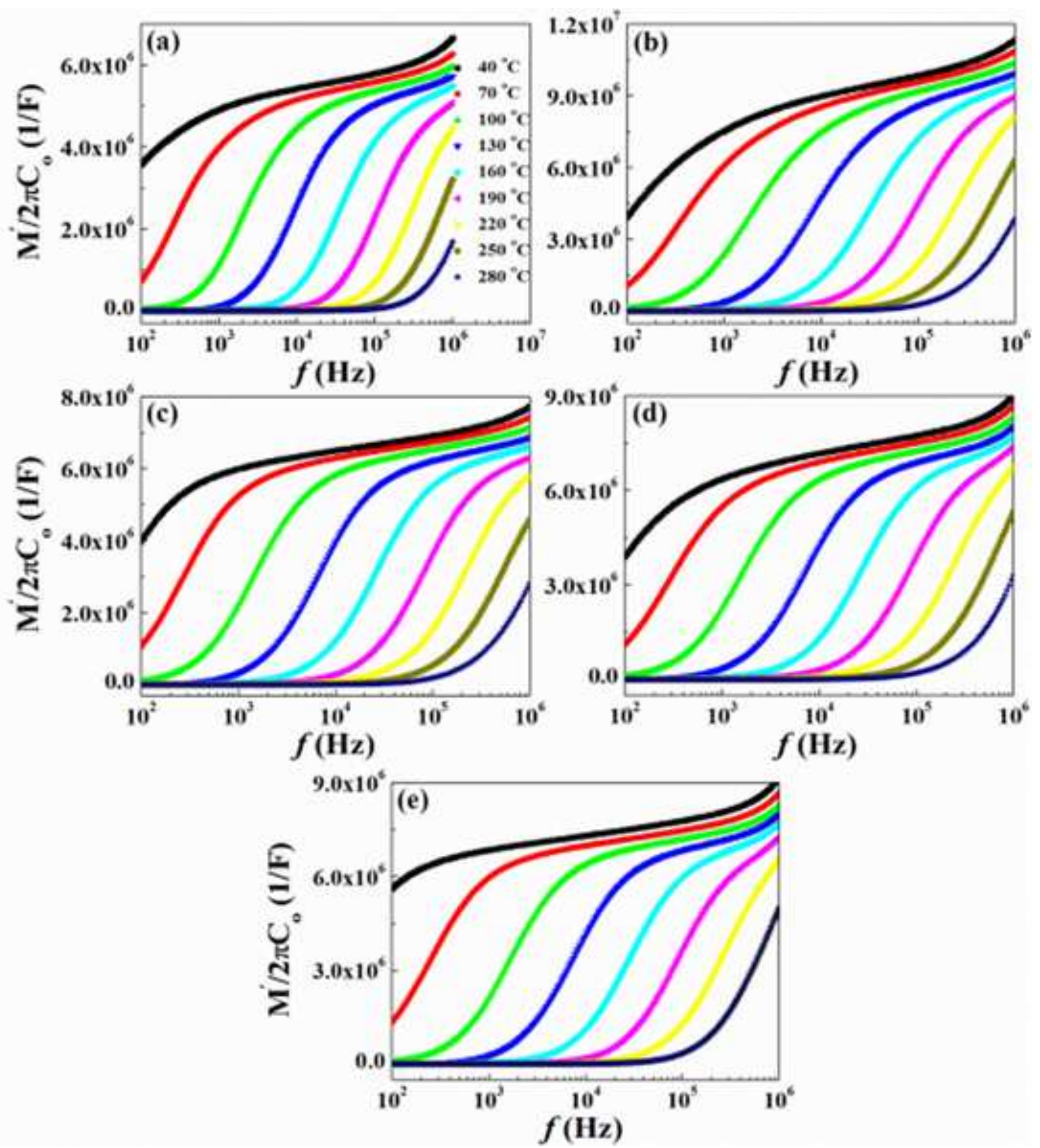

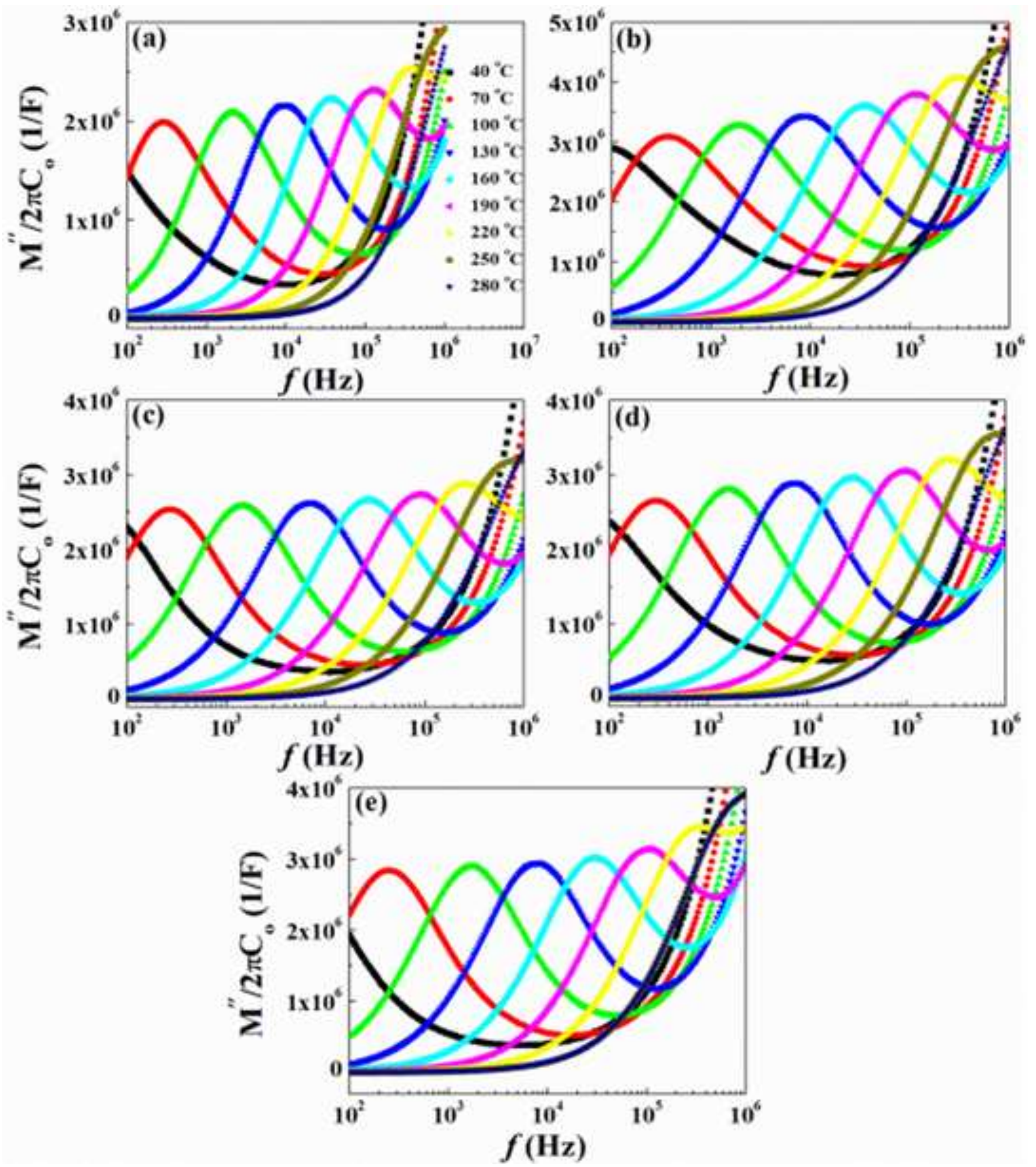

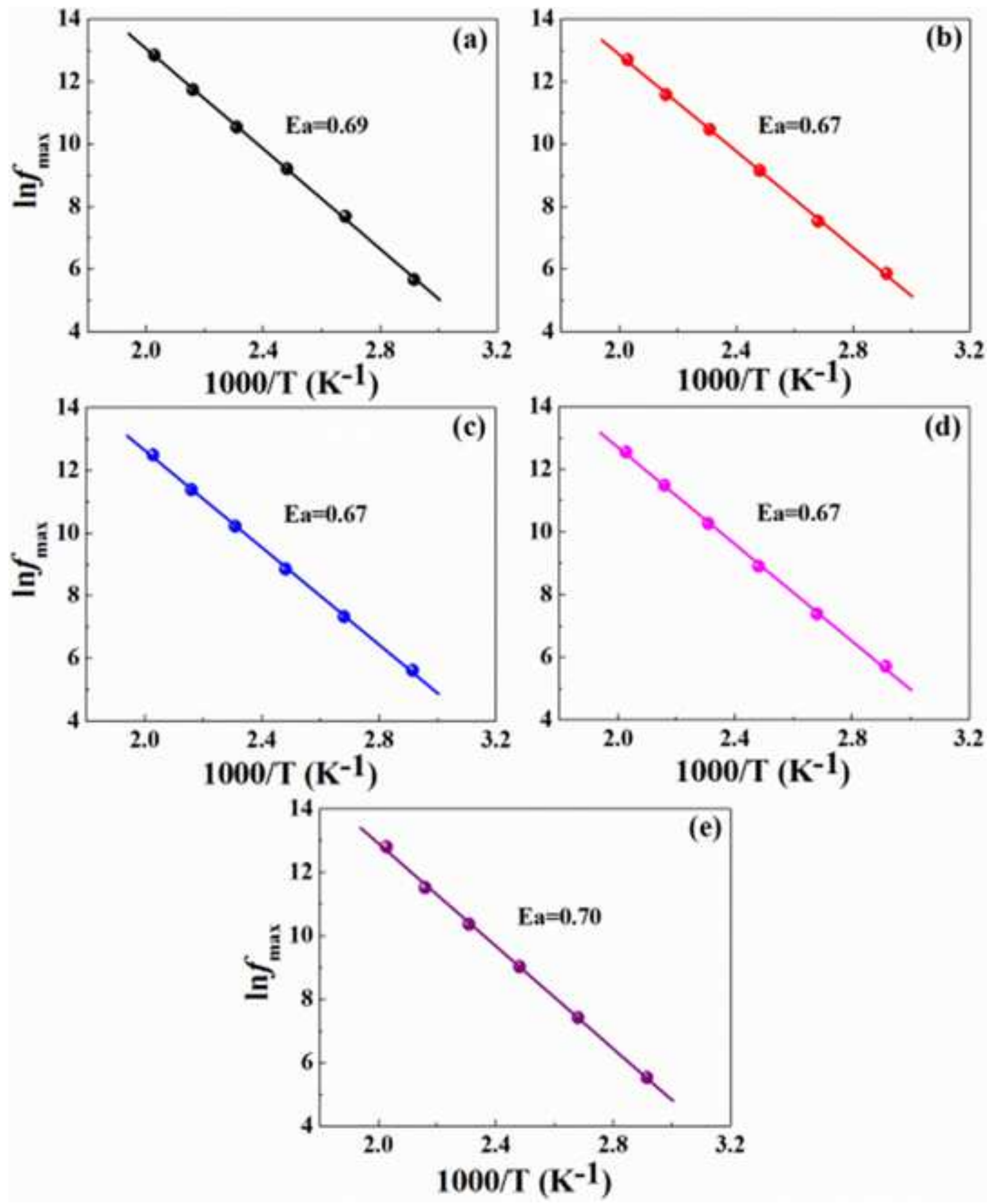


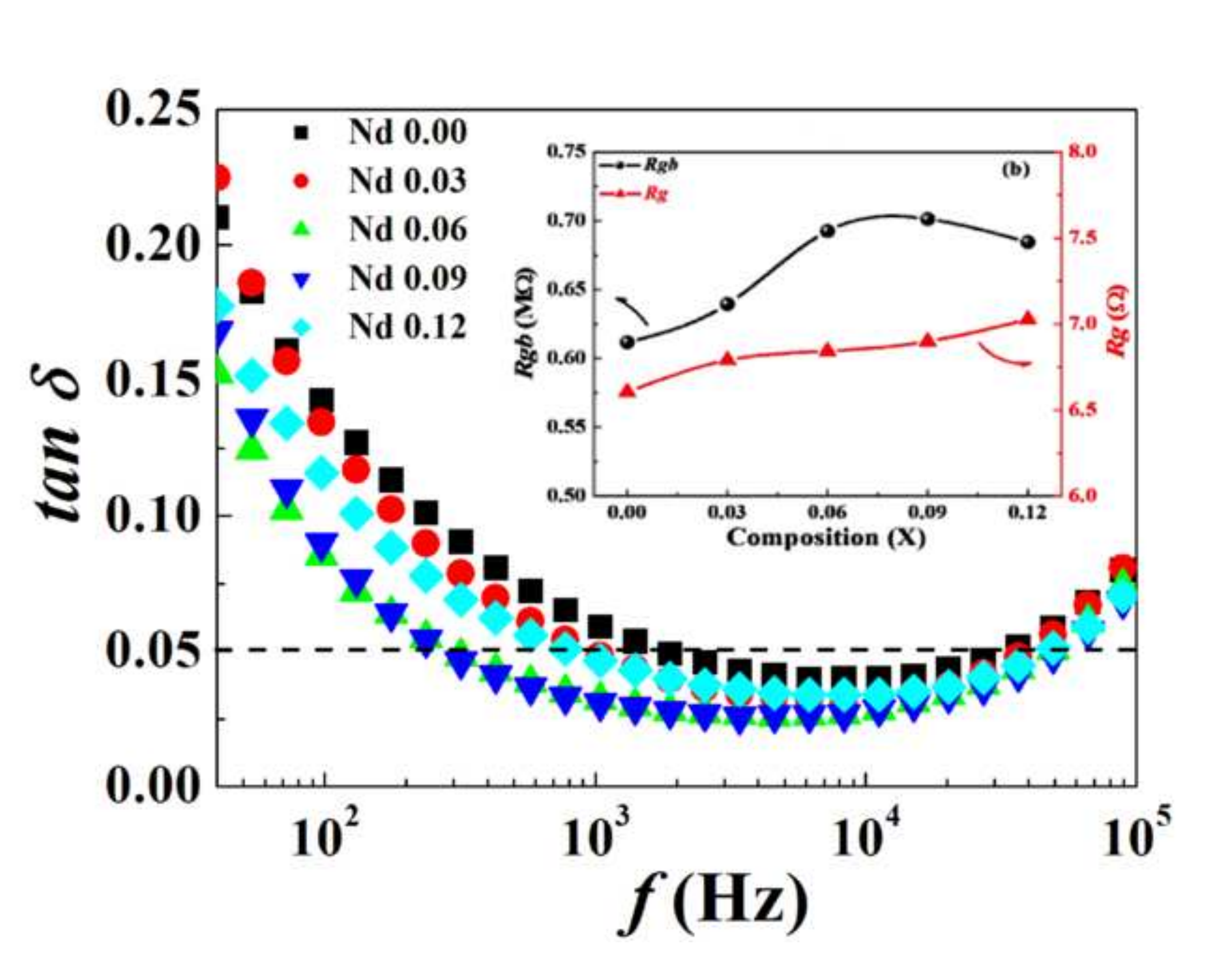

\footnotetext{
.

